International Review of Research in Open and Distributed Learning Volume 17, Number 2

February - 2016

\title{
Comparative Analysis of Pedagogical Strategies Across Disciplines in Open Distance Learning at Unisa
}

Kemlall Ramdass ${ }^{1}$ and Fulufhelo Masithulela ${ }^{1}$

1 University of South Africa, College of Science, Engineering and Technology, School of Engineering, Department of Mechanical and Industrial Engineering, Florida, South Africa.

\begin{abstract}
Re-engineering technological strategies in teaching and learning in an open distance learning (ODL) environment is paramount as the demand for access to quality higher education escalates drastically on a year to year basis. The organisational framework requires change in order to accommodate the increasing number of students. In view of the changing higher education landscape and the increase in the number of students qualifying for higher education acceptance, open distance education has been opened to residential institutions. Despite the fact that demands is greater than supply in the higher education sector, the University of South Africa (Unisa), in reaction to the "competitive threat," has embarked on the re-evaluation of ODL as a component of its teaching and learning methodology. Unisa focussed on its pedagogical approaches as a primary means of maintaining its competitive edge. The challenges in the higher education sector are also attributed to the basic education sector that does not prepare students sufficiently for higher education. ODL, if applied appropriately, could be a strategy to address the issues of access, equality, and equity in a democratic South Africa. Pedagogical strategies that are functional and appropriate need to be applied in the higher education sector. Hence the research question is to determine what ODL strategies can be implemented to ensure that students are on par with traditional universities. Therefore, this paper explores the pedagogical strategies that colleges may use with the intent to improve delivery of teaching and learning in an ODL environment.
\end{abstract}

Keywords: pedagogical strategies open distance learning, engineering ODL, teaching and learning 


\section{Introduction}

In the context of "old pedagogies" the teacher was assessed primarily on the ability to effectively disseminate information in the form of knowledge. The "new pedagogies" may be defined briefly as a framework of learning collaborations between teachers and teachers, students and teachers, students and students, students and society, thus aspiring towards a deeper insight into core learning objectives through information and communication technologies (ICTs). It is important to note that new pedagogies are not new teaching strategies but the reengineering of current strategies that would enhance the graduate of students and prepare them sufficiently for the work world.

Reengineering pedagogical strategies would mean the examination of the teacher's repertoire of teaching strategies, thus enabling constructive discussion among stakeholders through partnerships in the process of mastering subject content and its application. Learning does not end in the classroom, but continues outside the classroom, through the application of technology, thus enabling deep learning and creating new knowledge.

Information and communication technologies may be recognised as a support service that offer facilitation and collaboration that enrich the learning experience through record keeping, tracking student progress, timely discussion, and feedback during the learning experience. Therefore, the appropriate technology applications among all stakeholders may be used as an instructional tool that will enhance the learning experience of the student in particular. In order to accommodate the myriad of student diversity experienced in ODL, the university has adopted the blended approach to student learning. As per Unisa's definition, blended learning is the combination of contact, distance, and e-learning opportunities to suit different purposes, audiences, and contexts. Thus, blended learning requires appropriate pedagogical characteristics in emerging technologies where there are ways in which face-to-face teaching outcomes are integrated into the ODL environment.

Founded in 1873, the University of the Cape of Good Hope was renamed University of South Africa in 1916. As a specialist in distance education, Unisa's role was promulgated in 1946 with the offering of a wide spectrum of qualifications. With the dispensation of mergers in 2004, Professor Kader Asmal publicly pronounced that Unisa merge with Technikon South Africa (TSA) and the distance segments of Vista University. Today, Unisa has approximately 360,000 students in its eight colleges. As the sole provider of distance education in the country, Unisa has become a mega distance education university that is required to meet the changing demands of students, staff, and society. Technology has become the focal driver in education where quality service provision and student throughput improvement are the primary concerns. Recently, the South African Minister of Higher Education and training has announced that Unisa was no longer the single provider of distance education in the country. Other public universities are now permitted to provide distance education.

\section{Research Methodology}

The current study adopted a qualitative methodology, hence a multiple-case study, to determine strategies currently applied across colleges and to propose what could be done to improve service to students in their teaching and learning. Complex phenomena are studied through the application of qualitative case 
study methodology, which postulates the relevant tools that can be applied within their contexts. With the appropriate application of the case study approach, there is theory development, situation evaluation, and the development of interventions. Case study methodology funnels down an expansive research field into a single researchable theme. Although a research question may not be answered comprehensively it will provide theory and allow sufficient amplification to conclude the topic. Scientific theories and models are tested through the application of the case study research design. The study was conducted through invitation to discussions and focus group interviews. Literature reviews were also conducted as a theoretical underpinning of the research.

An extensive magnitude of data were attained through discussions with the various colleges. In this instance, the process was ignited by whether Unisa should go fully online. Consultant professional Neil Butcher was appointed to investigate and make recommendations regarding the organisational architecture of Unisa and the way forward. Through discussions, the Centre for Professional Development was harnessed to evaluate the pedagogical strategies of the colleges. Thus invitations through emails were sent through the Centre of Professional Development to college management. College management and staff and the Centre for Professional Development held discussions and focus group interviews where the focus was on the pedagogical strategy of the university that was looking at the modes of delivery of teaching and learning and how it could be more effective. The staff were divided into groups and asked to discuss and present answers to the questions that were posed.

\section{Literature Review}

"A surprising number of innovations fail not because of some fatal technological flaw or because the market isn't ready. ... Most often the very skills that propel an organization to succeed in sustaining circumstances systematically bungle the best ideas for disruptive growth" (Christensen \& Raynor, 2013, pp. 22).

The digital era is bringing about fundamental changes in all aspects of education. It is changing the role of teachers who are the primary source of content knowledge and the role of students who ought to be ardent listeners. Technology enables both the teacher and the learner to discover new sources of knowledge more cheaply from authentic sources. The application of knowledge was done and demonstrated through experiments, task orientation and problem solving in order to validate the mastery of theories studied. The education system fails societal requirements when solutions are bound within the classroom. Thus universities are required to expose students to the world of work. There is a real potential for ICTs to add value to the education system through simulation. New methods and models on learning and innovation, entrepreneurship, creativity, and collaboration both nationally and internationally are enabled through ground breaking technological advancements. It is important to note that this is applicable to all educational institutions, both ODL and traditional institutions (Spalding, Wilson, \& Mewborn, 2002).

Teaching and learning has two major stakeholders-the teacher and the student. Student needs, aspirations, and expectations are changing towards the use of digital and Web technologies, thus focusing on new ways of learning. Traditional teaching and learning, and thinking and doing is being challenged through the face of disruptive and constructive forces (Christensen, Horn, \& Staker, 2012; Rodriguez, 1998). 
Higher education institutions are facing limitations in its ability to adopt emerging technologies and innovation in learning. This is highly complex in that it needs institutional change, individual change, and technological change (Hrabowski, 2014; Hrabowski, Suess, \& Fritz, 2011; Salmon, 2014; Salmon \& Wright, 2013). Higher education (HE) face a major challenge in terms of organizational change to improve learning experiences of students and teachers and to prepare graduates at the level that is required by industry (Weller \& Anderson, 2013; Westera, 2004).

MOOCs (massive open online courses) have been the latest opportunity globally to attract attention in alternative ways of learning design (Daniel, 2012; Grimmelmann, 2012). There has been constant change in higher education (HE) over the past 50 years, both nationally and internationally (Davis et al., 2014; De Knop \& Gilquin, 2015; Gonzailez-Gonzailez \& Jimanez-Zarco, 2014; Herbst \& Kosko, 2014; Mackness, Waite, Roberts, \& Lovegrove, 2013). It needs to be noted that the political and economic landscape of a country determines the progress of education. Leadership of an organization guides the change according to policies from the department of higher education. Resilience and patience are required in the transformation process while maintaining purpose, functionality, and sustainability and this may take decades (Crabtree, Sapp, \& Licona, 2009; Jobe, Östlund, \& Svensson, 2014).

There is a desire to provide access to education to all people in South Africa, however; this is easier as it is a complex phenomenon. Higher education institutions (HEIs) are passionate about quality and equity, but are we achieving this? Financial implications, together with the will to change staff, are one of the largest challenges for HEIs. A global competitive environment and the drive to achieve in an environment where there is constant change in standards are difficult (Nichols, Phipps, Hewitt, \& Provencal, 2013). Academics are facing challenges in the workload of teaching and learning, community engagement, and research with goal posts changing on a regular basis.

National policies and reforms are necessary in order to guide this transformation process. Although the country has embarked on the renewal of telecommunications policies, the process seems to be slow. The human connection cannot be removed from the teaching and learning process and replaced by information technology, although it has the potential to deliver high quality content more cost-effectively. This requires teachers to be competent in the application of information technology, the philosophy of teaching, as well as content proficient so that the job can be done efficiently. Learning cannot be achieved without resolute human intrusion through learning design, pedagogical input, and technology.

\section{Analysis of Theoretical Implications for Unisa}

Interestingly, it is Peters (1993), who postulated the industrial model, who asks whether there are "early signs of a 'new era', which might be called 'post-industrial'?” (p. 40). Garrison (1997) alluded that distance education is moving into a post-industrial era where there is description to personalize the educational transaction. This is attained through two-way communication of learners in the context of the community (Garrison, 2000).

Teaching and learning practice at Unisa is underpinned by theory and affords the intellect necessary for effectual action (Garrison, 2000). The institutional structures create an enabling environment that guide the educational decisions to efficiently facilitate the learning experience within the context of distance 
education. However, this may not be sufficient, therefore theory must provide a comprehensible collation of pertinent variables and correlations to direct both practitioners and researchers in this field of distance education.

Although the definitions of theory are problematic (Garrison, 2000) it provides a basis in the organization of ideas that profile practice. This ultimately facilitates the prediction of emerging trends through analysis and reflection. The educational experience is reflected in theoretical constructs of distance education theory that is purposeful and spontaneous. The evolving methodologies of distance education are reflected through high-tech communications technology that bolster synchronous and asynchronous communication through communities of inquiry. Distance education theorists are in a continuous conundrum as how to adapt current theories to new realities, and where appropriate, create new theory (Garrison, 2000).

Unisa's teaching and learning philosophy is continuously challenged, therefore; it is important to review theoretical contributions of selected influential authors to gauge the current status quo in Unisa. In this regard, the review and analysis will move the organizational and distance realm to issues of transaction and education. (Garrison, 2000).

\section{Major Theoretical Contributions}

Numerous deliberations and reflections were postulated in the formulation of ODL pedagogy by a number of authors such as Keegan (1993), Garrison (1985), and Moore (1993). It was mentioned that the literature in distance education gave emphasis on the influence of technology between groups and generations of distance education provisions. However, there were deliberations on how proprietorship, transfer modes, syllabuses, instructions as well as the changing roles of academia and the students transformed over decades (Heydenrych and Prinsloo, 2010). It is noteworthy that the selection of teaching strategies was based on epistemological principles and postulations concerning how learning occurs, ranging from teaching as transmission, to transactional to transformational. Embedded in these three metaframeworks are different learning theories such as behaviourism, cognitivism or rationalism, constructivism, constructionism, social constructivism, connectivism, and other hybrid models of learning theory. Learning theories give us perspectives and see the mind as a black box where repletion and reinforcement takes place, as a computer where there is recall of information, and also as a rhizome where knowledge building takes place. John Dewey believes that education is a process of living and not a preparation for the future.

Behaviourist perspectives, as the term implies, is related to behaviour. Thus this perspective is related to the change in behaviour from stimulus-response in associations made by the learner from experiences. As a result of a stimulus a learner obtains new or changed behaviour. This needs to be reinforced through reward or punishment. Learners only respond to the stimulus provided.

Cognitivist perspectives is where the mind is seen as an information processor-how information is received, stored, and organized. Cognitivism is developed in response to behaviourism. Learning happens when as a result of brain processes, knowledge transfers from short to long-term memory. The teacher is the organizer, attention getter, so that the learner can store the information in short term memory. The 
brain must process, store, locate and produce responses to the information thereby creating new and evolving schema. Cognitivism is best suited for materials like charts and diagrams within the context of well-organized study guides, centres, and labs. Learners need to be immersed in challenging fearless environment. New information must be linked to prior knowledge. Information and concepts must be well organized (Salmon, 2014).

Constructivism is involved with actively engaging the learners. Salmon and Wright (2013) write:

Learning occurs when information is moved to long term while learners are involved with the process of creating their own knowledge based on experience with teachers as models. Learners are active and judge their own progress. Learners pull from past experience and connect to new ideas, usually by collaborating with others. (42)

The authors equate learning with creating meaning from experience where there is interaction with a problem or concept. This may be done through role play or debating current issues, thereby leading to higher order thinking (Salmon \& Wright, 2013).

Piaget, Cook, and Norton (1952) mention that learners develop different ways of perceiving, interpreting, and gaining meaning at different stages through a sequence of cognitive levels. Thus it is perceived that the maturing brain develops flexible frameworks into which we assimilate knowledge and experience; these frameworks are conceptual networks or schemas. Knowledge is thus constructed in the mind of the learner.

In view of the distinctions between adult learning (andragogy), self-determined learning (heutagogy), and methodologies of teaching (pedagogy) the ODL philosophy will attempt to assimilate characteristics of all three areas. (Hase \& Kenyon, 2000) have been criticized for their linear approach of self-directed learning. Heutagogy focuses on outcomes and competencies, which I believe is pertinent for the twentyfirst century student. "Capable people are more likely to be able to deal effectively with the turbulent environment in which they live by possessing an 'all round' capacity centred on self-efficacy, knowing how to learn, creativity, the ability to use competencies in novel as well as familiar situations and working with others" (Hase \& Kenyon, 2000, pp. 120).

Northedge (2003) alludes to the fact that knowledge is derived from interaction between knowledgeable people. There is an assumption that communities of practice (COP) or professional personnel groupings deliberating on particular issues foster common meaning and understanding of issues. It needs to be noted that the premise of ODL encourages student engagement in the workplace as the majority of ODL students are employed and in a discourse community where there is varying degree of professional conversations. Students participate both vicariously, as listeners and readers, as well as generatively, as speakers and writers, in order to develop an identity for themselves. This enables students from diverse backgrounds to share their insights on the subject matter.

The review of the theoretical contributions of Wedemeyer (1971) moved from the perception of "correspondence study" and "focused instead on independent study or learning" which promulgates foci on educational matters relating to learning at a distance (Wedemeyer, 1971). Thus Wedemeyer (1971) 
focused on the individual as the core of the teaching and learning process which he believed was "a democratic social ideal" (p. 549) of allowing everyone the prospect of learning. Coherent with the principles of equity and access, independent study was reliant on self-direction learning and selfregulation under geographical and temporal control of the learner. Wedemeyer (1971) also advocated that the learner has freedom of choice in the process of knowledge building and mentioned that independent study offers less freedom in "goal determination and activity selection" (p.551). He critiqued "the practice of not individualizing and questioned the seeming rigidity of the format and materials [that] apparently deters teachers and students from more completely exercising their respective options" (p. 551). He insisted that the "independent study method is not, in its basic concepts, different from other teachinglearning methods" (p. 553).

A hallmark of Wedemeyer's work was his "contribution to the establishment of the British Open University [BOU]" (Sherow \& Wedemeyer, 1990, p.18). Through the Articulated Instructional Media (AIM) project initiated by Wedemeyer in 1964, it "was proposed that a unique system be developed for a new type of institution and be made possible through course design utilizing media and technology and supported by counselling, resource and learning centres" (Sherow \& Wedemeyer, 1990, p. 18). As a pioneer in the advocacy of distance education, Charles Wedemeyer's principles in AIM were the theme of his lectures throughout the United Kingdom in 1965.

Another contributor from BOU was Otto Peters who analysed distance education through the lens of operations management, and suggested the application of methodologies such as division of labour, mass production, economies of scale, and unit costs (Peters \& Keegan, 1994). Although the focus moved to the operations strategy of distance education, he was influential in the organization of distance education at BOU in the 1970s. (Peters \& Keegan, 1994) explain the industrial approach as "objectification of the teaching process" (p. 111). According to (Peters \& Keegan, 1994), it "reduces the forms of shared learning, and keeps learners away from personal interactions and critical discourse” (p. 16). Peters' reasoning did not support the industrial approach for all of distance education. Thus, the prominence of organizational issues is focal to understanding the complexity in the delivery of distance education in the twenty-first century.

Core philosophical positions include three basic forms of academic learning: "self-learning, tele-learning and social intercourse" (Peters, 2000) p. 15). His advocacy is in the line of communications technology and lifelong learning where demands will precipitate a "transformation of the traditional university [and, presumably, all higher education] into an institution of self-study and distance teaching” (Peters, 200o, p. 20).

The reflections of (Garrison, Anderson, \& Archer, 2001) suggest that face-to-face is a challenging matter within a text-based interface. In review, (Garrison \& Anderson, 1999) argue that a text-based environment could have an intrinsic communications advantage in supporting critical discourse in a community of inquiry due to the communication characteristics being different and so would alter the educational experience. Nevertheless, there is a need to study the theory emerging from the spoken and written communication that would reinforce the educational process. Another pioneer in distance education theory who proposes the concept of guided didactic conversation which refers to real and simulated 
conversations where the focus of simulated conversation would be content and conversational in character (Holmberg, 1989a p. 43).

Accordingly, Holmberg (1989) argues that guided didactic conversation is a "pervasive characteristic of distance education" and his theory postulates that distance education is a friendly conversation that is fostered through well-developed self-instructional materials that enable a personal relation during study." (p. 43). Here, the expertise of course developers is required to create this simulated conversation through well-written materials. Holmberg's theory of distance education was directed to the pre-produced course package and clearly within the industrial paradigm. In essence, the principles of the industrial model and its reliance upon written communication as a core means of knowledge dissemination is a serious constraint and limits the role of interaction and the full emergence of a transactional perspective (Holmberg, 1989b).

Another theorist, Michael Moore, reviewed the structure of independent learning and added dialogue as a second variable in transactional distance education (Moore, 1991). It intuitively promotes and moves the field toward the realization of a pedagogical theory. He mentions that transactional distance is pedagogical and necessitates "special organizations and teaching procedures" (p. 3) which are comprised of two variables namely structure and dialogue (Moore, 1990);(Kearsley \& Moore, 1996). The structure of the course reflects design as an important variable in the teaching domain. Dialogue is focused on the medium of communication and may include two-way communication. Moore's theory promulgates that there should be low dialogue and low structure in distance education while face-to-face has high dialogue and high structure.

Moore (1993), and Moore and Kearsley (1996), imply that the greater the transactional distance, the greater responsibility is placed on the learner. Here they mention the personal characteristic of selfdirectedness and accountability as the learner defines objectives, procedures, resources, and evaluation in the teaching and learning process. On the other end of the continuum is teacher control. The schism appears to theorize structure and the learning materials above personal responsibility in teaching and learning.

In the evaluation of Moore's contribution, there is an attempt to combine characteristics of the industrial approach with the transactional approach where he states, "What we are normally referring to as distance education is a subset of all educational programmes, the subset characterised by greater structure, [and] lower dialogue" (Moore, 1990, p. 12). However, there is some confusion in his application of theory regarding the interrelationships among structure, dialog, and autonomy as well as his dialogue variables, clusters, and dimensions at various times. Future work needs to clarify this interrelationship amongst the variables and concepts of dialogue, structure and autonomy. Are these orthogonally related or do they overlap? In addition to the "infilling of the theoretical spaces" (Moore, 1990, p. 14), the creation of a visual model would enable clarification in the structural relationships among these concepts.

Henri's (1992) framework, which is a recent development in distance education, focuses on the learning process and the interaction between the learner and teacher. The model has five dimensions as its foundational characteristics and they are cognitive, metacognitive, participation, interaction, and social as the core characteristics of the framework. Henri's contribution alludes to collaboration as a key variable in 
the teaching and learning process and affords structure in the coding of messages to study the nature and quality of the discourse through the perspectives of psychosocial and transactional view through mediated communication.

It needs to be noted that basic contributions from prominent scholars in the field of distance education were extrapolated to underpin the theoretical perspectives in the development of the distance education mode of teaching and learning. It may be said with confidence that the theoretical development has gained ground and continues to develop into the twenty-first century. There are still major challenges in emerging technologies as the growth of distance education is proceeding at an alarming rate.

\section{Results and Discussion}

As per the research methodology, all colleges were invited to participate in discussions and focus group interviews to determine their current strategies and embark on re-engineering their pedagogical strategies in order to improve delivery of teaching and learning in ODL. In a discussion by management, it was revealed that teaching and learning fully online may be detrimental to students who are in rural locations where information and communication technologies are limited and sometimes do not exist. Thus the blended approach was adopted. It provides interactive, individual, flexible, and participative technology-based learning where students construct knowledge through intellectual engagement at their own pace. A blended learning framework refers to a blend of learning theory, teaching practice, student-centred learning, and the use of new technologies in order to provide students with rich, meaningful learning experiences that extend beyond the lecture room or discussion class.

The first question they had to answer in the bigger group was: Why is the university now asking them for a pedagogical framework? This question did not only open the discussion but also the problem space. Thereafter they were invited to describe their dream pedagogical model or strategy for the College of Agriculture and Environmental Sciences (CAES). The facilitation team unpacked their deliberations into the current challenges faced by the institution and explored their dream pedagogical strategy in point form:

1. How will we teach? College staff mentioned that the modes of delivery are informed by the purpose of what needs to be taught. It was posited that correspondence and being fully online is the way they want as the college would want to achieve. The constraint was that due to the divergent nature of the student background and the different learning styles of students; Unisa's strategy would be the blended mode of delivery. It is important to consider the context in which teaching occurs, where the dynamism is the rural student, the educational background of the student, student access to resources, students that are employed, as well as the binary divide in a comprehensive institution. More focus should be paid to problem-based learning and contentbased learning.

2. How would you like to communicate with your students? It was mentioned that there needs to be an expansion of communication technologies so as to respond to students immediately and 
develop a student association, utilise Facebook, webcam, video conference (VC), and student seminars to send both formal and informal information so that students become an active part of the college. Students need to be fully conversant on issues of plagiarism as there are students who plagiarise other students work. It was mentioned that assessment methodologies need to be evaluated.

3. Where will your primary teaching text be? It was mentioned that there needs to be a transition between 2015 and 2018 from paper-based to online on national qualification framework (NQF) Level 5 to 7. Learning resources should be readers, tutorials, myUnisa, eBook, myUnisa platform for MOOC's OER social network, webinars, and cloud technology. Technology is changing and Unisa needs to change with it.

4. Educational resources: where do we get our content from? It was noted that migration to online is moving very deliberately. Academics request the use of DVDs for practical use; videos where the student sees the face of the module and is guided through the learning units. Staff requested Unisapedia where there is a cycle of renewal, and industry stakeholders are invited to talk to students and also evaluate the content of the modules. Copyright issues are pertinent and needs evaluation as content is available and students need to navigate on myUnisa. Also, content should be accessible to students.

5. How will we foster active learning collaborations, and authentic, meaningful engagement that is reflexive? It was mentioned to engage students with basic knowledge and journey with them in groups with a tutor through a structured package for teaching and learning. In order to foster engagement, students would be motivated by some kind of prize for being the best engaged student which would bolster behavioural change in committed students. The provision of little bytes of information, understanding the student and their situations, and planning an engagement strategy would thus enforce engagement.

6. How will you assess the students to support learning that is meaningful and exciting? This can be done through the creation of variety in the module through multiple choice questions and the use of different assessment methods for different modules such as case studies, online, and practical as an example. In this endeavour the use of different activities such as Dropbox, PowerPoint, blogs, and social media would provide students with a platform that has flexibility with freedom where students take responsibility and accountability. Importantly, planning should take place a year in advance so that the process is thoroughly thought through. Often it becomes restrictive when lecturers communicate a week before assessment. Academics should have instant access to student information and student marks should be displayed on the notice board. There should be a platform for students to communicate to other students and lecturers. Also it was mentioned that screen size plays a role on what is learnt. Self-help tests should be given to students to assess themselves.

7. How will you assess the students to support learning that is meaningful and exciting? It was mentioned that orientation would be beneficial to all students through all Unisa centres. It would be important to perform diagnostic evaluation to determine student readiness and address the 
"gaps" through academic literacy. Student support requires evaluation to determine effectiveness of e-tutors, academic literacy, and all other forms of student support.

8. How will the above questions influence your curriculum? There need to be alignment of curricula as envisaged by the Higher Education Qualification Framework (HEQF) as well at internal coherence and alignment of modules. The development of curricula in an ODL context also considers notional hours and credits through institutional guidelines. The college posits the "arachnid" approach where enterprise content management (ECM) is at the centre to provide the platform with curriculum pedagogical strategies that are supported by authentic, relevant, reflexive, and responsive deep teaching and learning with quality assurance as an inclusive entity.

9. How will the above influence your curriculum/programme qualification mix. This would be done through the following activities:

- flexibility in all support functions and the use of alternative technology,

- an appropriate architecture for the organisation with information and communication technology as a focal point of departure considering open distance learning,

- alternative innovative assessment methodologies,

- reviewed and configured curriculum,

- integrated shared learning resources,

- simplified user-friendly systems,

- systems to support effective use of laboratories for teaching and research, and

- decentralised integrated support systems.

10. Which systems will support the dream of your college? The college postulated the following points:

- academics with the necessary teaching skills,

- alternative assessment agenda,

- ICT-related matters that are resolved as a matter of urgency,

- industry training where lecturers are allowed to spend time in industry for the latest technological application,

- the determination of what content can be put on the system,

- examinations as a central point for assessment,

- reduction in the amount of administration issues for lecturers,

- a focus by lecturers on teaching, learning, and research which should all have career paths to senior management.

11. The Human Resources Department needs to ensure that further appointments in academia should be lecturers with teaching experience in an ODL environment. The Centre for Professional Development would be required to reskill academics to be able to perform effectively.

12. What is the way forward? The following analogy was posited: "We are currently looking at a carriage where lecturers are trying to push and management is trying to pull but it has square 
wheels. Both management and lecturers are grappling with a problem that remains unresolved. From the outside we can see this and we need to change the wheels of the carriage to round wheels so that we can achieve our objectives."

It was mentioned that schools are progressing well in terms of online education, and we at the university are still struggling. Blackboard as a tool is an excellent module generator and needs to be considered in ODL. There needs to be major investment at Unisa in order to enable a progressive learning environment.

On evaluation of the blended approach as used by all colleges, it is important to note that colleges share the majority of the challenges described above. Colleges used this platform to reiterate the challenges they face and that management needs to understand these problems. The imperative is that Unisa needs to change and improve the current status through process mapping so as to focus on the delivery of teaching and learning. The challenges need to be addressed by the management of the institution.

\section{University's Role}

To affect the ODL pedagogical model, the university will need the following:

- transformation at all levels of the institution through a structured approach and plan that pronounces the mandate of the university and its deliverables;

- buy-in on all deliverables from all stakeholders;

- and action plan that outlines tasks and responsibilities of all personnel at Unisa;

- to ensure stable, reliable, scalable, affordable, and robust ICT platforms;

- to provide cloud technology and ensure bandwidth to underpin the model;

- to provide continuous (available over weekends and after hours) technical support, which should be available centrally, and also decentralised in the colleges and departments;

- to address Internet access issues on a nationwide scale both for staff and students;

- to lobby the government to ensure large-scale pressure on better and cheaper broadband access for students and staff;

- to exert pressure on cell phone companies for inexpensive access to $3 \mathrm{G}$ and $4 \mathrm{G}$ networks and this could be provided for free to all students who are studying on National student aid scheme (NSFAS) or Fundza Lushaka (as a hidden cost to students) through their fees;

- to ensure that students are provided with low cost (good quality) devices on their initial registration;

- to ensure that students attend compulsory computer competency classes which could be provided by external contractors (the minimum technical competences required for studying must be specified and communicated and supported);

- to ensure staff are provided with lap tops or tablets and $3 \mathrm{G}$ or $4 \mathrm{G}$ in order that they might be in a position to provide after-hour support to students;

- to ensure that support structures are enhanced to support the academics' implementation of elearning methodologies;

- to provide professional development in the form of training for technology and on the use of technology and technology-enhanced teaching; and 
- it is essential that all ICT subsystems (finance, registry, student records, teaching, and learning) are considered simultaneously so that the systems might interact with each other.

ICT is the backbone for ODL teaching and learning. Core organizational members need to be willing, eager, and committed to bring about change within the institution in order to improve the current situation. Management, support departments, and academia need to work together to implement ICT solutions that would incrementally improve teaching and learning in the university. The aim of the institution is to transform the institution to achieve more and better levels of teaching and learning, thereby excelling in the mandate.

A multiple strategy is required to achieve innovations in teaching and learning and may be summarized as follows:

- Pedagogical innovations: With support from government, industry and the SETAS, academics are required to design their curriculum to meet social and societal needs that would enable job creation.

- Systemic innovations: Working together to achieve the mandate of the institution through transformation and commitment.

- Transformation: The need to meet the obligations of all stakeholders.

In summary, a multiple strategy approach is needed to realize the classes of inventions in learning and teaching and these include:

- Systemic innovations-elevated, reachable strategies speaking a diversity of spectators and participants, with a strong proof base (Gregory \& Salmon, 2013; Gregory \& Wright, 2014).

- Pedagogical innovations-methods of addressing new tactics and methods in the education strategy. Appeal to staff to attain the necessary training to support exclusively digital and open learning (Gregory \& Salmon, 2013; Gregory \& Wright, 2014).

- Re-evaluation of theories and models for the entry of students into a digitally enhanced environment (Gregory \& Salmon, 2013; Gregory \& Wright, 2014).

\section{Conclusion and Recommendations}

In view of re-engineering the open distance landscape, it is imperative that concerted effort be applied to enhance teaching and learning through technological strategies in an open distance learning (ODL) environment. Globalisation of higher education requires an organisational framework that functions effectively in meeting the demands of society. Therefore this paper recommends the following in terms of findings:

The following conclusions and recommendations stem from our findings:

1. All universities have grasped a mixed learning methodology. Considering both current and proposed teaching and learning practices, it is no more reasonable to embrace onesize-fits-all ways to deal with teaching method or frameworks at Unisa. Therefore 
teaching and learning strategy with the respective pedagogy needs to be tailored to meet ODL requirements.

2. The methodologies proposed by schools are by and large officially all situated inside of Unisa's Open and Distance Learning (ODL) Charter and with the framework for an ODL pedagogy created in 2011. Thus, there ought to be no requirement for any philosophical or hypothetical re-working of these key standards, as they are already developed.

3. Colleges reflect solid consciousness of the assorted qualities and fluctuating monetary substances of Unisa's populace.

4. The most noteworthy oversight over the College pedagogical procedures is related to funding research of new teaching and learning methodologies. It will be progressively more critical to break down the monetary and human asset ramifications of presenting new teaching and learning methodologies.

5. Unisa's present authoritative reporting structure reduces teamwork among colleges that currently work in a silo philosophy. Thus it makes cooperation and correspondence over the colleges troublesome, while diminishing motivating forces for such joint effort.

6. Testing of developments of various types is hazardous, as there is no degree for organizing the procedure of testing new methodologies or advancements, measuring their relative viability, and after that methodically enlarging their utilization if they demonstrate effective. Most testing of instructive advancements seems to work on a profoundly individualized and specially appointed premise, instead of as a major aspect of a cognizant institutional system to organize sending of new, more successful teaching and learning routines on a reasonable and instructively compelling premise.

7. Initial investigation recognized 85 university boards that are as of now operational at Unisa. Of these, it was conceivable to find terms of reference (ToRs) for just 45. For the most part, ToRs don't unmistakably exhibit the degree to which they relate or seek after the university's central goal and vision.

8. A large amount of time is spent in meetings with negligible value being added. Time spent in gatherings was recognized by many as disappointing and a hindrance to teaching and learning.

9. Although Unisa's mixed teaching and learning model may make new chances to abuse the establishment's information and capacity to produce third-stream income, it is normal that the necessities of students are often overlooked.

10. Unisa's strategic plan proposes to best address the issues relating to teaching and learning, however the university will continue to operate in a mixed model approach towards teaching and learning.

11. The mixed teaching and learning model does not greatly impact plans of action for Unisa's examination exercises. Notwithstanding this, however, the digitization of key frameworks, upgrades in availability and correspondence frameworks, and compelling administration of scholarly capital inside of the college ought to all add to making Unisa essentially more profitable in its exploration.

12. It is necessary to concentrate on an outline of improved frameworks and concentrate on centre institutional needs, joined with decentralization of those frameworks where different, and changing, methodologies and advances are liable to be required by schools. 
Presently, Unisa's frameworks are vigorously unified in all regions, diminishing spryness and essentially expanding the dangers of universities presenting new teaching and learning procedures. This centralization likewise urges numerous scholastics to work outside the frameworks, which is counterproductive over the long term.

\section{References}

Bonk, C. J., Hansen, E. J., Grabner-Hagen, M. M., Lazar, S. A., \& Mirabelli, C. (1998). Time to connect: Synchronous and asynchronous case-based dialogue among preservice teachers. Electronic collaborators: Learner-centered technologies for literacy, apprenticeship, and discourse, 289314 .

Christensen, C., Horn, M., \& Staker, H. (2013). Is K-12 blended learning disruptive? An introduction of the theory of hybrids. Clayton Christensen Institute for Disruptive Innovation. Retrieved from http://www.christenseninstitute.org/publications/hybrids/

Christensen, C., \& Raynor, M. (2013). The innovator's solution: Creating and sustaining successful growth. Boston : Harvard Business Review Press.

Crabtree, R. D., Sapp, D. A., \& Licona, A. C. (2009). Feminist pedagogy: Looking back to move forward. In Crabtree, RD, Sapp, DA, \& Licona, AC (Eds.). (2009). Feminist pedagogy: Looking back to move forward. Baltimore: Johns Hopkins University Press.

Daniel, J. (2012). Making sense of MOOCs: Musings in a maze of myth, paradox and possibility. Journal of Interactive Media in Education, 2012(3), 18.

Davis, H. C., Dickens, K., Leon Urrutia, M., Vera, S. z., del Mar, M., \& White, S. (2014). MOOCs for Universities and Learners an analysis of motivating factors, e-print ID 363714.

Fabro, K. G. (1996). Computer conferencing in higher education: An exploration of communication and cognitive development issues: Educational Psychology, Thesis (M.Sc.), University of Calgary.

Garrison, D. R., Anderson, T., \& Archer, W. (2001). Critical thinking, cognitive presence, and computer conferencing in distance education. American Journal of Distance Education, 15(1), 7-23.

Garrison, D. R., \& Anderson, T. D. (1999). Avoiding the industrialization of research universities: Big and little distance education. American Journal of Distance Education, 13(2), 48-63.

González-González, I., \& Jiménez-Zarco, A. I. (2014). The MOOC phenomenon: the current situation and an alternative business model. eLearn Center Research Paper Series, (9), 26-33.

Grimmelmann, J. (2012). The merchants of MOOCs. Seton Hall Law Review, Forthcoming, 2014-2016. 
Hara, N., Bonk, C. J., \& Angeli, C. (2000). Content analysis of online discussion in an applied educational psychology course. Instructional Science, 28(2), 115-152.

Hara, N., Bonk, C. J., \& Angeli, C. (2000). Content analysis of online discussion in an applied educational psychology course. Instructional Science, 28(2), 115-152.

Hase, S., \& Kenyon, C. (2000). From andragogy to heutagogy. Ultibase Articles, 5(3), 1-10.

Herbst, P., \& Kosko, K. (2014). Mathematical knowledge for teaching and its specificity to high school geometry instruction. In Research trends in mathematics teacher education (pp. 23-45). Springer International Publishing.

Holmberg, B. R. (1989a). The concept, basic character and development potentials of distance education. Distance Education, 1O(1), 127-134.

Holmberg, B. (1989). Key issues in distance education: An academic viewpoint. European Journal of education, 24(1), 11-23.

Hrabowski, F. A. (2014). institutional change in higher education: innovation and collaboration. Peabody Journal of Education, 89(3), 291-304.

Hrabowski III, F. A., Suess, J., \& Fritz, J. (2011). Assessment and Analytics in Institutional Transformation. Educause Review, 46(5), 14.

Hrabowski, F. A., Suess, J., \& Fritz, J. (2011). Assessment and analytics in institutional transformation. Educause Review, 46(5), 14.

Jobe, W., Östlund, C., \& Svensson, L. (2014). MOOCs for professional teacher development. In Society for Information Technology \& Teacher Education International Conference, Mar 17, 2014 in Jacksonville, Florida, United States (pp. 1580-1586). AACE.

Moore, M. G., \& Kearsley, G. (2011). Distance education: A systems view of online learning. Third edition, Wadsworth, Cengage Learning. USA

Mackness, J., Waite, M., Roberts, G., \& Lovegrove, E. (2013). Learning in a small, task-oriented, connectivist MOOC: Pedagogical issues and implications for higher education. The International Review of Research in Open and Distributed Learning, 14(4).

McDonald, J., \& Gibson, C. C. (1998). Interpersonal dynamics and group development in computer conferencing. American Journal of Distance Education, 12(1), 7-25.

Moore, M. (1990). Recent contributions to the theory of distance education. Open Learning, 5(3), 10-15. 
Nichols, N., Phipps, D. J., Provençal, J., \& Hewitt, A. (2013). Knowledge mobilization, collaboration, and social innovation: Leveraging investments in higher education. Canadian Journal of Nonprofit and Social Economy Research, 4(1), 25.

Peters, O. (2000). The transformation of the university into an institution of independent learning. Changing University Teaching: Reflections on Creating Educational Technologies, 6(7) 10-23.

Peters, O., \& Keegan, D. (1994). Otto Peters on distance education: The industrialization of teaching and learning: New York: Routledge.

Piaget, J., Cook, M., \& Norton, W. W. (1952). The origins of intelligence in children (Vol. 8). New York: International Universities Press.

Rodriguez, A. J. (1998). Strategies for counter resistance: Toward socio-transformative constructivism and learning to teach science for diversity and for understanding. Journal of Research in Science Teaching, 35(6), 589-622.

Salmon, G. (2014). Learning innovation: A framework for transformation. European Journal of Open, Distance and E-Learning, 17(2), 220-236.

Salmon, G., \& Wright, P. (2013). Transforming future teaching through a Carpe Diema earning design. Education Sciences, 4(1), 52-63.

Sherow, S., \& Wedemeyer, C. A. (1990). Origins of distance education in the United States. Education at a Distance: From Issues to Practice, 4(3) 7-22.

Spalding, E., Wilson, A., \& Mewborn, D. (2002). Demystifying reflection: A study of pedagogical strategies that encourage reflective journal writing. The Teachers College Record, 104(7), 1393-1421.

Wedemeyer, C. A. (1971). Independent study. The Encyclopaedia of Education, 4, 548-557.

Weller, M., \& Anderson, T. (2013). Digital resilience in higher education. European Journal of Open, Distance and E-Learning, 16(1), 53.

Westera, W. (2004). On strategies of educational innovation: Between substitution and transformation. Higher Education, 47(4), 501-517.

Heydenrych, J. F., \& Prinsloo, P. (2010). Revisiting the five generations of distance education: Quo vadis? Progressio, 32(1).

Northedge, A. (2003). Enabling participation in academic discourse. Teaching in Higher Education, 8(2), 169-180. 
Gregory, J., \& Salmon, G. (2013). Professional development for online university teaching. Distance Education, 34(3), 256-270.

Moore, M. G., \& Kearsley, G. (1996). Distance education: A systems approach. Boston, MA: Wadsworth.

Henri, F. (1992). Computer conferencing and content analysis (pp. 117-136). Berlin: Springer.

Garrison, R. (2000). Theoretical challenges for distance education in the 21st century: A shift from structural to transactional issues. The International Review of Research in Open and Distributed Learning, 1(1).

Peters, M. (1997). Education and the postmodern condition. Westport: Praeger Publishers.

Garrison, D. R. (1997). Self-directed learning: Toward a comprehensive model. Adult education quarterly, 48(1), 18-33.

Moore, M. G. (1991, May). Theory of distance education. In Second American Symposium on Research in Distance Education, (22).

Keegan, D. (1993). Reintegration of the teaching acts. Theoretical Principles of Distance Education, 113.

Moore, M. G. (1993). Theory of transactional distance. Theoretical Principles of Distance Education, 22.

\section{Athabasca}

University

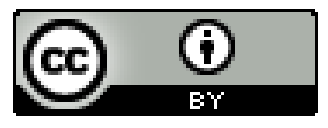

